\title{
EL ARQUITECTO JUAN DE MINJARES EN GRANADA
}

\author{
por RAFaEl LóPEZ GuZMÁN
}

\begin{abstract}
Juan de Minjares, un arquitecto perteneciente al círculo de Juan de Herrera, lleva a cabo alteraciones en el Palacio de Carlos V en Granada, modificando el proyecto de Pedro Machuca. Se proporciona mayor información sobre el arquitecto, que construyó el Archivo de Indias de Sevilla y trabajó con Juan de Herrera en El Escorial.
\end{abstract}

Juan de Minjares, an architect belonging to the circle of Juan de Herrera, carried out alterations to the palace of Carlos V in Granada, modifying the the project by Pedro Machuca. This provides further information on the architect, who built the Archive of the Indies in Seville and worked with Juan de Herrera on the Escorial.

La presencia de Juan de Minjares en Andalucía se produce paralelamente al interés de Felipe II por extender un modelo arquitectónico unitario como era la fábrica del Escorial. Formado en los círculos herrerianos ${ }^{1}$ había sido aparejador del palacio de Aranjuez, del Hospital de Afuera de Toledo ${ }^{2}$ y de la iglesia, fachada y pórtico principal del monasterio del Escorial desde $1576^{3}$ hasta $1583^{4}$. A partir de aquí se instituye en la persona de confianza, tanto de Juan de Herrera como del monarca, destacada en el italianizado sur. Así, se desprende que fuera enviado a Sevilla para dirigir las obras de la Lonja con traza del arquitecto del Escorial ${ }^{5}$, desconfiado hacia otros maestros locales.

1. Cfr. WILKINSON, C. Juan de Minjares and the Reform of Spanish Architecture under Philip II. "Actas del XXIII Congreso Internacional de Historia del Arte". Tomo II. págs. 443-448.

The Career of Juan de Mijares and the Reform of Spanish Architecture under Philip II. "Journal of the Society of Architecture Historians" (1974) n. 33. págs. 122-132.

2. KUBLER, G. La obra del Escorial. Madrid, Alianza, 1982. pág. 113.

3. GOMEZ-MORENO, M. palacio del emperador Carlos V en la Alhambra. Madrid, El Correo, 1885 , pág. 16.

CHUECA GOITIA, F. Arquitectura del siglo XVI. "Ars Hispaniae", Vol. XI. Madrid, Plus Ultra, 1953. pág. 368.

4. LLAGUNO Y AMIROLA, E. Noticias de los arquitectos y arquitectura de España desde su Restauración. Madrid, Imprenta Real, 1829. Vol. II. pág. 123.

5. CHUECA GOITIA, F. Op. cit. pág. 337. 
Establecido en la ciudad del Guadalquivir, se le encargará la dirección de las obras de la Alhambra de Granada tras el óbito de Juan de Orea, por cédula de 19 de noviembre de 1583 , cargo que ostentó hasta su muerte en $1599^{\circ}$.

Juan de Orea, casado con una hija de Pedro Machuca ${ }^{7}$, había sido nombrado maestro mayor de la Alhambra al fallecer Luis Machuca ${ }^{8}$. No obstante, la paralización sufrida tras la expulsión de los moriscos que subvencionaban las obras le impidió avanzar la construcción. Sus continuas protestas exigiendo recursos económicos fueron desoídas, a la vez que se enfrentaba con Juan de Herrera al mantener las ideas directrices de los Machuca frente al intento del monarca de finalizar cuanto antes un edificio que le incomodaba, reduciendo, en lo posible, costes, para lo que se eliminaría la parte decorativa no necesaria ${ }^{9}$.

Minjares supone en Granada el ejecutor de los criterios de Herrera modificando el proyecto de Pedro Machuca. Centrará su actividad en la construcción del piso alto de la portada oeste del palacio ${ }^{10}$. En esta, el centro debería presentar tres luces conformando, posiblemente, una estructura serliana como en la portada sur, lo que fue reducido a un sólo vano. En total encontramos tres ventanas, coronadas con frontones (curvos los externos y triangular el central), enmarcadas por pilastras jónicas y, sobre ellas, tres tondos, resaltados con molduras de piedra serpentina, que inscriben relieves en mármol blanco de la Sierra de Filabres (Almería), donde se representa a Hércules luchando contra el León de Nemea y el Toro de Creta, reservando el espacio central para la heráldica real.

El trabajo escultórico se debe a Andrés de Ocampo, escultor sevillano de prestigio, que fue contratado en esa ciudad directamente por Juan de Minjares, marginando a los tallistas granadinos del momento ${ }^{11}$.

La nueva fase de las obras en el palacio se había reanudado en 1581 con un censo de 6.000 ducados anuales procedente de las rentas de los Alcázares de Sevilla que, hasta entonces, estaba asignado al Alcázar de Toledo ${ }^{12}$. Esta cantidad suponía un detrimento en 4.000 ducados respecto a lo que aportaban los moriscos inicialmente. Es de suponer, por tanto, que este recorte en el presupuesto supusiera una de las razones más importantes en el proceso de desaceleración de los trabajos en relación con el período anterior al levantamiento de las Alpujarras y la consiguiente expulsión de los moriscos.

6. GOMEZ-MORENO, M. Op. cit. pág. 16.

7. MARTINEZ RUIZ, J. El taller de Juan de Orea. "Cuadernos de la Alhambra" (1965) n.. 1. pág. 59-74.

8. Archivo General de Simancas. Casa y Sitios Reales. Leg. 265. Fol. 76.

9. Archivo de la Alhambra L-21-3.

10. Archivo de la Alhambra L-6-20.

11. Archivo de la Alhambra L-210-4.

12. GOMEZ-MORENO, M. Op. cit. pág. 17. 
El papel de Minjares en la Alhambra es discutible. Entre 1584 y 1591 eleva el segundo cuerpo referido de la portada oeste ${ }^{13}$. El zaguán del mismo lado lo ejecutó entre 1592 y $1595^{14}$. En 1593 construye la galería del piso superior del patio ${ }^{15}$. En 1594 se trabajó en el piso alto del lado Este y de la capilla, comenzando la portada de este lateral en $1596^{16}$. Por fin, en 1598 comenzaban las labores del lado norte ${ }^{17}$.

Hemos de precisar la restricción de los temas ornamentales con la eliminación casi total de la talla escultórica si exceptuamos la cornisa alta con acanto, rosetas y cabeza de león; a la vez se introdujo un nuevo elemento decorativo como era la piedra serpentina proveniente de las canteras del río Genil, situada, puntualmente, en los basamentos y tondos del cuerpo superior de la portada oeste que, pese a la cercanía del yacimiento, se utilizaban por primera vez. Ahora bien, para Minjares no era este un elemento desconocido, ya que desde Granada se llevaron para la decoración de la Capilla Mayor de la iglesia del Escorial ${ }^{18}$.

En segundo lugar hemos de decir que el levantamiento del piso alto del patio se realizó con las columnas que ya habían sido labradas en época de Luis Machuca ${ }^{19}$, lo que invalida, en parte, la actividad de Minjares.

Por último, diremos que no llegó a culminar las instrucciones de Herrera que presuponían una cubierta emplomada: “...de la manera que está hecho en Aranjuez y en el Escorial..." 20 .

Estas precisiones suponen un serio interrogante sobre la actividad, a priori importante, que se produjo en los años de dirección de Juan de Minjares. Además, debemos poner de manifiesto la figura del aparejador Juan de la Vega. Su eficacia se pondrá de manifiesto cuando a la muerte de Minjares no se nombre un nuevo maestro mayor, sino que Juan de la Vega asumirá las funciones sin ascender de cargo, aunque si de sueldo que pasó de siete reales y medio a ocho reales y medio ${ }^{21}$, prorrogándose esta situación hasta su muerte en 1612 en que será nombrado maestro mayor Pedro Velasco ${ }^{22}$.

13. Archivo de la Alhambra L-240-7 y L-52-1.

14. Archivo de la Alhambra L-52-1.

15. Ibidem.

16. Archivo de la Alhambra. L-52-1.

17. Archivo de la Alhambra L-83.

18. CERVERA VERA, L. Años del primer matrimonio de Juan de Herrera. Valencia, Albatros, 1985. págs. 36 y 81 .

19. GOMEZ-MORENO, M. Op. cit. pág.13.

20. Archivo de la Alhambra L-6-11.

21. Archivo de la Alhambra L-21-4.

22. Archivo General de Simancas. Tribunal Mayor de Cuentas Leg. 1576. 
La importancia del aparejador se magnifica si tenemos en cuenta las continuas ausencias de Minjares para atender a las obras sevillanas. Estas, aunque no siempre, comprenden los inviernos, mas suaves en Sevilla, pasando los veranos en Granada. Por ejemplo, en 1585 no estuvo desde enero a octubre, con el parentesis de una visita entre el 9 y el 16 de marzo. En 1586 estuvo ausente desde enero al 29 de marzo y desde el 9 de abril al 19 de julio. Posteriormente, marchó a Sevilla el 4 de octubre volviendo en julio de 1587 . Tras el verano, en septiembre, se ausentó regresando en julio de $1588^{23}$.

Como vemos las ausencias son excesivamente prolongadas como para ejercer una dirección efectiva de las obras. Esta situación, incluso, provocaba bastante malestar entre los obreros de la Alhambra como refleja una queja presentada por el Veedor de las obras el 29 de agosto de 1597. En ella dice: “...que no acude a la obra sino dos o tres meses del verano por huir del calor de Sevilla por gozar de las nieves y buenas bevidas que ahy aquí, se levanta a las 9 y se viene a la Contaduría y se sienta y pone las piernas en otra silla, y se está en conversación contando cuentos y quejándose de que no se le dan ayuda de costas y a la tarde acude a las obras a ordenar y mandar sin dar cuenta de ninguna cosa ni al alcaide y veedor, de aquí resulta lo poco de la obra porque lo que va prosiguiendo su aparejador consultado ya con él muchas veces le parece mal y se contradicen de que resultan daños". ${ }^{24}$.

Aparte del Palacio de Carlos V, Juan de Minjares, se ocupará en 1590 de realizar una memoria sobre los reparos necesarios tras la explosión del polvorín de San Pedro que afectó, sobre todo, a elementos secundarios como cristales, puertas, cerraduras y tejas, siendo menor el daño en lo arquitectónico centrado, casi exclusivamente, en la Sala de los Mocarabes del Palacio de los Leones ${ }^{25}$.

En 1596 realizó un informe para la adecuación de un aljibe de la Alcazaba para suministro de agua a los habitantes de este sector de la Alhambra alejado de los puntos de suministro existentes ${ }^{26}$.

Por último, en la ciudad participó en el informe realizado sobre el cuerpo octogonal de la torre de la catedral junto a Diego de Vergara, Alonso Barba, Ambrosio de Vico, Juan de la Vega, Pedro Orea y Martín Díaz de Navarrete, acordando recalzar los cimientos, derribar la parte ochavada que se estaba terminando, desmontar las bóvedas y macizar la escalera y los arcos grandes del primer y segundo cuerpo ${ }^{27}$.

23. Instituto Gómez-Moreno. Leg. 101, Fol. 60.

24. Instituto Gómez-Moreno. Leg. 101, Fol. 86-87.

25. Archivo General de Simancas. Casa y Sitios Reales. Leg. 265, Fol. 130.

26. Archivo General de Simancas. Casa y Sitios Reales. Leg. 265. Fol. 121.

27. GOMEZ-MORENO, M. Guía de Granada. Granada, Imp. Indalecio Ventura, 1892. pág. 262. 


\section{APENDICE DOCUMENTAL}

\section{DOCUMENTO 1}

1585, Enero, 26. Alcalá.

Cédula real otorgando a Juan de Minjares la merced de 350 ducados para su ayuda de costa.

\section{A. Alh. L-47-12.}

"El Rey:

Don Gaspar de León, nuestro Pagador de las obras del Alhambra y casas reales de Granada, yo vos mando que de qualesquier maravedís de vuestro cargo deys y pagueys a Juán de Minjares, Maestro Mayor dellas, o a quien su poder oviere , tresçientos y çincuenta ducados, que montan çiento y treynta y un mill dozientos y çinquenta maravedís, de que le hazemos merced por una vez para su ayuda de costa, acatando lo que nos a servido; y tomad su carta de pago o de quien el dicho su poder oviere con la qual y esta nuestra çedula tomando la razón della Alonso Arrias Riquelme, Veedor de las dichas obras, mando se os resçiban y pasen en quenta los dichos tresçientos y cinquenta ducados sin otro recaudo alguno. Fecha en Alcalá a veynte y seys de henero de mill y quinientos y ochenta y çinco años. Yo el Rey, por mandado de su Magestad, Mateo Vazquez.

Alonso Arias Riquelme. (rubricado)".

\section{DOCUMENTO 2}

1589, (s.m.), (s.d.). (Alhambra).

Memoria de las losas de mármol que Damian Plan, cantero, tiene que sacar de las canteras de Filabres.

\section{A. Alh. L-6-20.}

"Memoria de las losas de mármol que Damian Plan, cantero, a de sacar en las canteras de Filabres y traer a esta Alhambra para las obras reales della son las siguientes:

Veynte y çinco baras de canales para el quarto de lo leones, conforme a la planta que va señalada en un borrador que es pie y diez dedos de ancho, y medio pie de grueso y a la rebaxarla quatro dedos de hondo, y un pie menos tres dedos de ancho la canal y los largos dellas, como salieren acomodadas en la cantera con que no sea ninguna menor que de dos pies y medio de largo.

(al margen): XX V.

Mas sacará veynte y çinco baras de lossas rassas que tendrán de ancho dos pies y medio cada una, y de gruesso quatro dedos y el largo como saliere en la cantera con que no sea ninguna de menos que de dos pies y medio que vendrá a ser quadrado y de allí arriba lo que cada una tuviere como las canales. 
(al margen): XX V.

Mas sacará doze pieças para los vazíos de entre los Leones conforme a una plantilla que va señalada en una borrador con la de las canales que tendrá cada una desde el ángulo que haze en el medio della tres pies y tres quartos de largo, y los lados pequeños tendrá cada uno un pie y dos dedos, y la frente del dicho ángulo que le es opuesto un pie menos dos dedos, y los lados largos tres pies y diez dedos, y de gruesso tendrá cada una un quarto de pie bien entregado.

(al margen). X II.

Mas sacará dos lossas de a quatro pies y tres quartos de pie de largo, y un pie y tres quartos de pie de ancho, y un quarto de pie de gruesso para las dichas cassas Reales.

(al margen): II

Todas las pieças dichas an de ser muy blancas y bien entregadas sin lebantes, ni vetas feas, ni manchas, ni desportilladuras y bien desbastadas y derechas.

Mas sacará quatro lossas para los lados del escudo que viene dentro del tondo del medio de la fachada, con quatro pies y medio cada lado del quadrado, y una buelta escarçana como va en la planta del borrador, y las puntas tendrán de ancho diez dedos, cada una con medio pie de gruesso, y en la bondad, y blancura, y bien entregadas, y sin pelos, ni levantes, y en lo demás sean tales que no se puedan mejorar.

(al margen): IIII.

Assimismo sacará tres pieças para el escudo y para los dos espejos de los lados que tendrá cada una seys pies y dos dedos de diámetro, y pie y un quarto de pie de gruesso son redondos an de ser de mármol, lo más blanco que se pueda hallar y sanos, y bien entregados, y desbastados sin ninguna desportilladura, ni mancha, ni fealdad, ni pelo, ni veta, ni levante y sanas.

(al margen): III.

Joan de Mijares." (rubricado).

\section{DOCUMENTO 3}

1591, Agosto, 31. Alhambra.

Ajuste de las cuentas con Andrés de Ocampo.

A. Alh. L-210-4.

"En el Alhambra de Granada en postrero día de agosto de 1591 años, con yntervención de Alonso Arias Riquelme, veedor de las dichas obras y de Joan de Mijares, maestro mayor dellas, Don Gaspar de León, Pagador de las dichas obras del dinero Real arca del Rey Nuestro Señor, pagó a Andrés de Ocampo, escultor, vecino de Sivilla una librança su fecha este dicho día, mes y año de cantidad de mill y trecientos y treynta y un reales que valen, quarenta y çinco mill docientos y cinquenta y quatro maravedies, que los ubo de aver por razón de averse concertado con él porque así convino la manifactura de relieve del escudo prinçipal de las armas reales, y las dos ystorias de Hércules de los espejos colaterales del dicho escudo, de la sigunda ordenança de la fachada prinçipal de las dichas cassas reales nuevas, en piedra mármol blanco, el qual conçierto hizo con el suso dicho en 
la dicha çiudad de Sevilla Joan de Mijares, maestro mayor de las dichas obras, por comisión que para ello tubo de don Miguel Ponçe de León, teniente de Alcayde de la dicha Alhambra y de Alonso Arias Riquelme, veedor de las dichas obras por convenir así que se buscase oficial tal qual requiere la perfección de la dicha obra de escultura, por quantía de quatroçientos y treinta ducados de vaxo de çiertas condiçiones como paresce más largo por la escritura que dello otorgó y ratificó en la dicha Alhambra, en presencia y con yntervención de los susodichos Don Miguel Ponçe de León, teniente de Alcayde y Alonso Riquelme y Joan de Mijares, y ante Bartolomé de León, escrivano de la dicha Alhambra, y por quanto entre las condiçiones de la dicha escritura son que avía de dar pulimento al dicho escudo y espejos, y averse acordado que no se dé el dicho pulimento por no llevarle los espejos de la primera ordenança, ni las demás pieças de mármol blanco, que van en la dicha fachada se le vajan veinte ducados, en que se tasó el dicho pulimento, de los quatroçientos y treynta ducados en que se conçertó la dicha manifactura, y asimismo se le vajan tres ducados por averle aguzado las herramientas con que labró el dicho escudo y espejos el herrero que su Magestad tiene en las dichas obras, y porque asimismo fue condicion que acabada la dicha obra, la viesen ofiçiales de escultura si está conforme a las dichas condiçiones se nombró a Pablo de Rojas, escultor, vecino desta çiudad, para que con juramento declarase si, el dicho Andrés de Ocampo, avía cumplido con ellas, el qual en presençia de los dichos ofiçiales mayores y escrivano, declaró, estar acabada la dicha obra conforme la dicha escritura y condiçiones, se le libró la dicha cantidad con la qual y con çiento y seis mill noveçientos y sesenta y quatro maravedies que tiene rescividos por buena quenta de la dicha manifactura por dos libranças una de çinquenta y tres mill quatroçientos y ochenta y dos maravedies, su fecha en quatro de Julio de este presente año de quinientos y noventa y uno, y otra de otros tantos maravedies, su fecha en tres de agosto del suso dicho se le acabó de pagar la dicha partida por entero".

\section{DOCUMENTO 4}

1594, Agosto, 6. Alhambra.

Condiciones para sacar y desbatar la piedra de Sierra Elvira para la cornisa del patio del Palacio de Carlos $V$

\section{A. Alh. L-6-39.}

"Las condiçiones con que se a de sacar y desbastar la piedra parda de la Sierra Elvira para el cornisamento de la segunda ordenança del patio del Quarto nuebo son las siguientes:

Primeramente el offiçial o offiçiales que se encargaren de sacar y desbastar la dicha piedra, la an de sacar y desbastar conforme a los contramoldes que para ello se les darán, que an de ser de los primeros contramoldes en que bienen el alquitrabe y frisso, çiento y veynte y ocho pieças. 


\section{(al margen) CXXVIII.}

Mas se an de sacar para la corona del dicho comisamento sesenta y quatro pieças, conforme a los contramoldes que para ello se les darán, las quales ellas, y las de ariba dichas, an de yr desbastadas cada una dellas con tres contramoldes que se darán a entender a la persona o personas que se encargaren de sacar la dicha piedra.

(al margen) LXIIII.

Es condiçion que la dicha piedra a de ser toda de un color granimenuda, sin que tenga vetas ningunas blancas ni de otra color, y sin pelos, ni levante ni atronadura, muy bien desbastada, derecha y a esquadría, sin ninguna desportilladura, todo muy bien entregado de piedra dura a contento, y si alguna piedra no fuere de recibir y se truxere a la dicha Alhambra pagarán lo que costare de traer y no se le recibirá la dicha piedra y en rematándosele la dicha piedra, an de hazer luego escritura y dar fianças a contento del veedor de la dicha fábrica, y lo an de començar a sacar luego y no an de alçar mano dello hasta averlo acabado.

En el Alhambra de la Cibdad de Granada, a seis días del mes de agosto de mill e quinientos e noventa y quatro años, Alonso Arias Riquelme, vehedor de las obras reales desta Alhambra, y Juan de Mijares, maestro mayor dellas, mandaron que Garçía López, pregonero de Granada, pregone la piedra contenida en las condiciones de arriva, atento que es menester para el affeto contenido arriva en las dichas condiciones, y así lo mandaron y firmaron de sus nombres. Joan de Mijares, Alonso Arias Riquelme." (rubricado). 


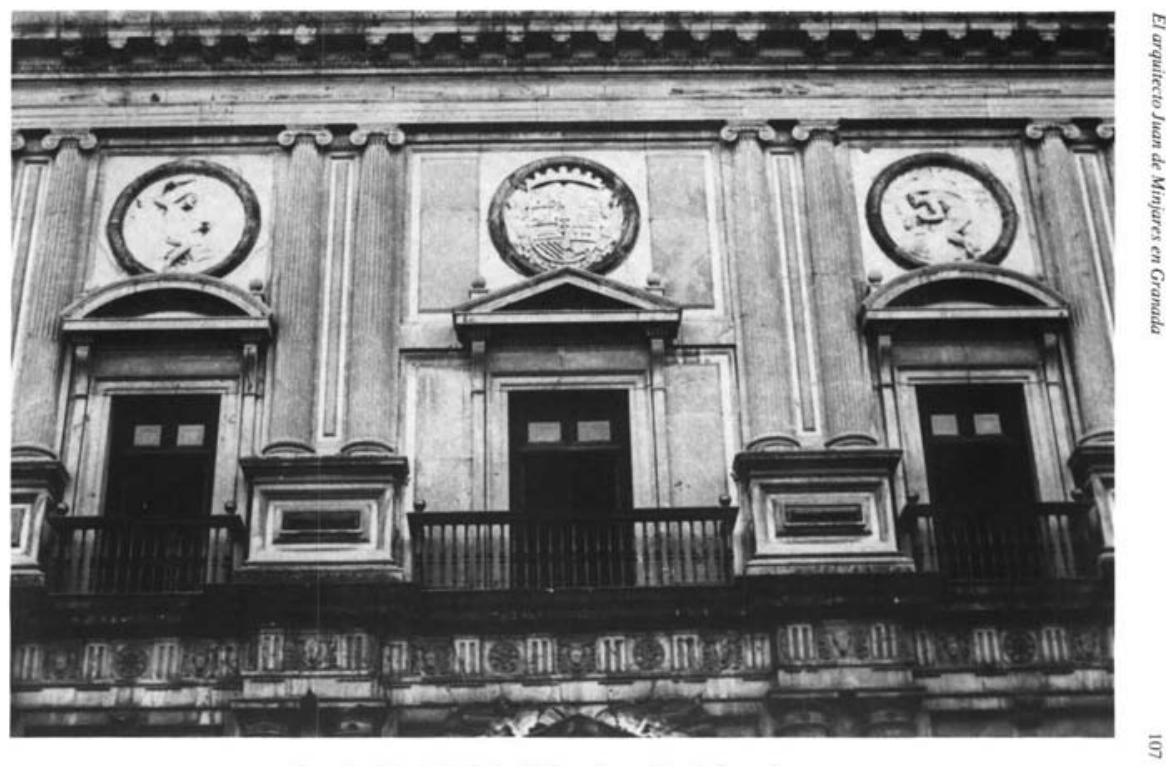

Granada. Palacio de Carlos V. Portada occidental. Segundo cuerpo. 


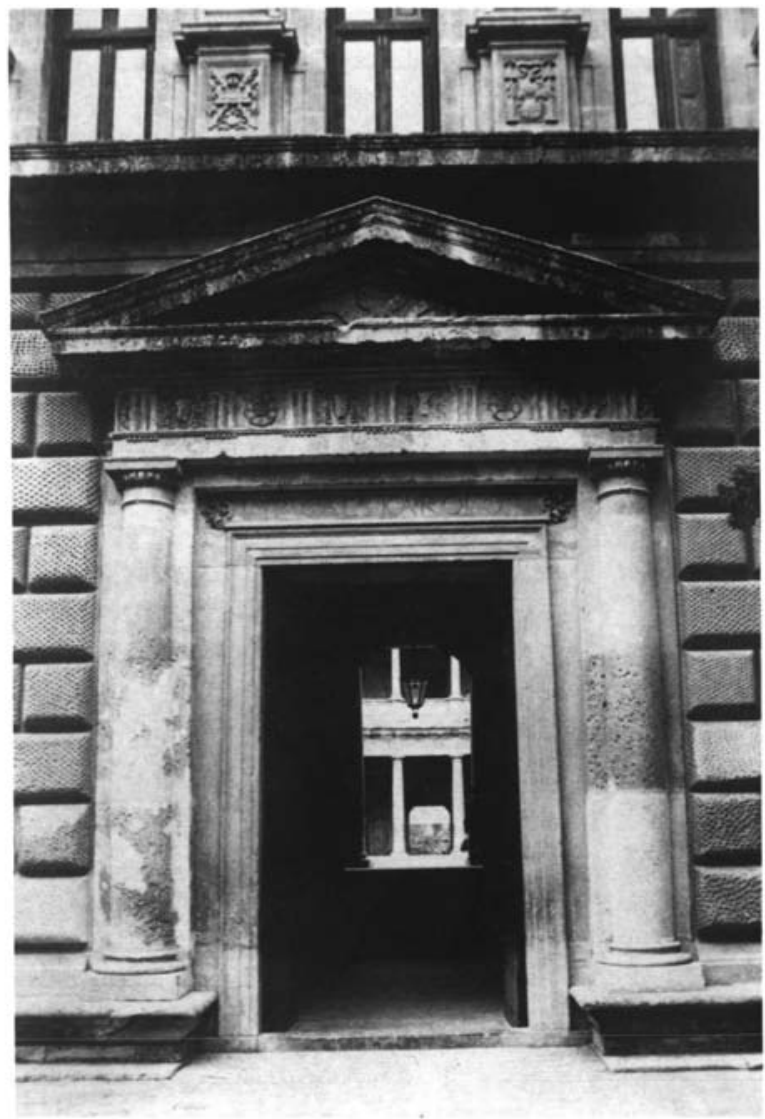

Granada. Palacio de Carlos V. Portada oriental. 


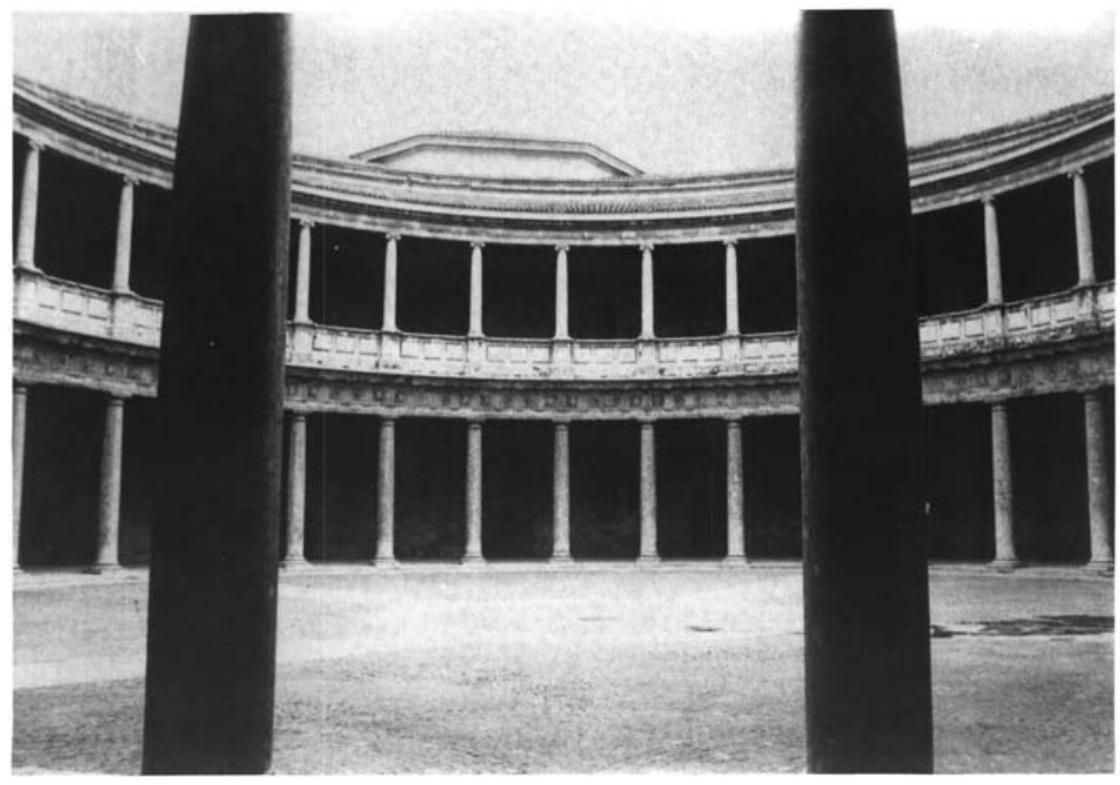

